\title{
EL INCESTO EN CIEN AÑOS DE SOLEDAD: ¿UN CAMINO LIBERADOR HACIA LA INTEGRACIÓN DE LA ESTIRPE?
}

\section{Kattia Chinchilla Sánchez}

\begin{abstract}
In García Márquez One Hundred Years of Solitude incest is the most studied aspect and all the authors deduce that it was the punishment of a family sentenced to "one hundred years of solitude". I present a new version of this topic: incest is a true way to freedom and psychological integration, because the pig's tail combine both natures, human and animal, without being either completely; however, it displays the conscious and unconsciuos zones in a unit form. Finally, the baby-monster will probably become a new being who has the jungan selbst, far away from the terrible solitude.
\end{abstract}

"Porque a los dioses les gusta el enigma y les repugna lo que es manifiesto".

Upanishad

\section{Introducción}

Desde su publicación, en 1967, Cien años de soledad nació para provocar todo tipo de comentarios y, especialmente, abundante "hermenéutica". Se observa el fin del libro y el principio de la escritura, como un movimiento de infinita reflexión en sí misma, amén de su estructura circular o urobórica. Esto le permite a la escritura asumir una conmoción de posible apertura en la significación. El mismo García Márquez visualiza el libro como una especie de base para el acertijo o crucigrama, sin especificar mayor cosa sobre esto último. Mas Lois Marie Jaeck propone que una vez completo el rompecabezas, Cien años de soledad sería una representación de la escritura en su estado puro, como ficción absoluta en cuanto a una realidad no definida desde fuera, sino dentro de sí misma. Paradójicamente sólo a través de la clausura (la muerte del libro) puede nacer el texto como escritura con un movimiento abierto de significación. Jacques Derrida ha demostrado cómo la escritura se constituye en un sistema no-centrado de significación, al rechazar abiertamente el marcado logocentrismo occidental:

"Writing is repetition, repetition is death, and death is the begining, as the loss of the "center' extends the movement of signification of the non-centeresystem to infinity." (Jaeck 1991: 51) 
Cien años de soledad contiene "el libro en (dentro) el libro". El manuscrito de Melquíades predice que la aniquilación de la raza de los Buenđía y la ciudad de los espejos y espejismos ocurrirá en el preciso momento en que Aureliano Babilonia termine de descifrar los pergaminos. La lectura de Aureliano de los pergaminos del gitano, en el libro donde su familia ha estado viviendo y en el cual su autor ha ido escribiendo, es el instante en el cual el libro viviente (la estirpe Buendía) y el libro escrito (manuscritos) se reconocen a sí mismos como dobles gemelos:

Era la historia de la familia, escrita por Melquíades hasta en sus detalles más triviales, con cien años de anticipación. La había redactado en sánscrito, que era su lengua materna, y había cifrado los versos pares con la clave privada del emperador Augusto, y los impares con las claves militares lacedemonias. García Márquez 1971: 349)

El término desconstrucción nos indica que todo texto tiene en sí la capacidad de invertir, subvertir o contradecir sus propios significados. Estamos hablando no de una lectura monológica sino de un juego o alternancia de los elementos opuestos (el residuo de "undecidability", que la lógica no puede resolver). Desconstruir es un evidenciar, un tratar de determinar, un explicitar lo que se ha podido o querido disimular, prohibir o marginar. G. Douglas Atkins (en Camacho Ramírez 1990: 7) nos dice:

(...) deconstruction consists of an undoing/preserving that, produces ceaseless reversal reinscription, and oscilation of hierachical terms.

Es un deseo de-velar, y hasta revelar, lo que cubre el tejido literario (texto), en procura de nuevos tejidos, que bien podríamos ver materializado en las célebres muñecas rusas (machuscas). ¿Habrá un carácter críptico en el lenguaje? Hillis Miller opina que:

(...) all languaje is figurative all the begining. The notion of a literal or referential use of languaje in only an illusion born of the forgetting of the metaphorical "roots" of languaje. (en Camacho Ramírez 1990: 10)

Borges dice que cada lector crea su intertextualidad: todo libro es un diálogo infinito, como se aprecia en esta cita:

(...) es más que una estructura verbal, o que una serie de estructuras verbales; es el diálogo que entable con su lector y la entonación que impone a su voz y las cambiantes y durables imágenes que deja en su memoria. Ese diálogo es infinito (...) (Borges en Sacerio-Gari 1987: 62)

Para Bajtín el mundo es dominado por la heteroglosia, o sea, la presencia de múltiples lenguajes o discursos que chocan y tratan de imponerse (en cierta medida se asemeja al juego del centro y el suplemento):

(...) el característico modo espistemológico de un mundo dominado por la heteroglosia. Todo significa, se comprende como parte de un todo más grande -hay una constante interacción entre los significados de los cuales todos son capaces de condicionar a los otros. El que afecta al otro, cómo lo hará y hasta qué pun- 
to, todo esto se determina en el momento mismo de la enunciación. El imperativo dialógico, garantizado por la preexistencia del mundo del lenguaje relativo a cualquiera de sus habitantes actuales, asegura que en realidad no puede haber ningún monólogo. (Bajtín en Sims 1988: 52)

La heteroglosia desencadena una serie de fuerzas centrípetas y centrifugas que chocan continuamente porque hay una constante interacción entre significados y el significado del enunciado es determinado por las circunstancias existentes en el momento en que se emitió.

En términos panorámicos, los conceptos de Bajtín se pueden resumir en dos ejes:

1.) mundo carnavalesco-dialogismo-fuerzas centrifugas-heteroglosia.

2.) mundo oficial-monologismo-fuerzas centrípetas-lenguaje unitario.

Con base en lo que nos interesa, la novela Cien años de soledad, al primer eje pertenecen la idea de tiempo (mítico, universal, circular) y de incesto (como fuerza centrífuga, marginal, suplemento). Empero, el segundo eje también está presente en el texto: la negación de la matanza de los 3.000 huelguistas en Macondo, la guerra civil y la participación del coronel Aureliano Buendía, el imperio del banano por parte de los estadounidenses, entre otros.

Richard Watson (1987: 89) afirma que es claro que el contenido de la novela de García Márquez es que la vida y la muerte son una misma cosa:

One is born to die, and all of live is movement toward that goal. The biggest problem is while away your time while getting from birth to death. (...) Life goes on and death in inevitable.

Aquí podemos postular lo siguiente: la vida se define por la presencia (logocentrismo, sustentado en Descartes), pero al aplicar la différance, nos damos cuenta que, en realidad, la vida es la negación de la muerte, o bien su ausencia. ¡He aquí el juego o movimiento relacional! Șegún nuestros temas elegidos, hay un tiempo e incesto iniciales, que generan la "vida" de la estirpe de los Buendía. Pero, a la vez, hay un tiempo e incesto postreros, que ponen punto final a la familia ("muerte"). Volviendo a la afirmación del autor supra citado, en el pensamiento mítico-religioso es claro que vida y muerte se suceden, para dar paso a un renacimiento, sea material o espiritual. Nos alejamos, con esto, de la dialéctica sin resolución o aporía derridiana.

El suplemento "suple", es una plenitud que enriquece a otra (el colmo de la presencia). No se añade para reemplazar. Se insinúa un "en-lugar-de": se llena, se colma un vacío. El incesto es una prohibición impuesta, en la novela del Premio Nobel de Literatura 1982, por Ursula (una matriarca, el centro de la familia Buendía). Así es considerado, sólo en su aspecto tabuado. Nos proponemos diseñar y explicitar un suplemento para esta plenitud consabida ("el incesto y su producto son la causa directa de la caída de la estirpe"), un lado críptico, dormido, marginado, soslayado, anidado en lo inconsciente colectivo. Proponemos que el incesto es, más bien, la liberación del estigma de la soledad y una imagen mítica (o mito literario) de la integración de la psique o selbst, teoría de Carl Gustav Jung. 


\section{Teorías sobre el incesto y algunos antecedentes literarios}

El incesto ha sido por siglos uno de los tabúes de la sociedad occidental; tabú, sólo en el sentido de una prohibición total, como ocurre en las religiones represivas de Israel y el Cristianismo, pero también, es un tabú social, como acontece en muchas sociedades primitivas y en las familias reales de Europa. Como han apuntado D.W. Cory y R.E.L. Masters (en Levine 1975: 108), en su estudio:

Un acto tabú como el incesto, puede ser completamente prohibido, pero también puede tener un castigo sagrado, y estar por lo tanto reservado a ciertas personas, o ciertas ocasiones (...) Entre los pueblos de la antigüedad (y en algunos de la edad moderna), las relaciones incestuosas eran reservadas para las ocasiones de significación sagrada. En tales ocasiones, el incesto no era meramente tolerado sino que hasta podía ser obligatorio.

Durante el Renacimiento italiano, las prohibiciones del incesto eran a menudo ignoradas. Se atribuía conducta incestuosa a los Papas (como el famoso Alejandro VI), a dignatarios de la Iglesia y a muchos nobles. Esta actitud encontraba paralelo en una literatura en la cual el incesto era tomado a la ligera y hasta era mirado con humor.

A lo largo de los siglos, el incesto ha despertado sentimientos poderosos de repulsión y de atracción en los seres humanos. Esta intensidad de la reacción universal ante el incesto ha fascinado no sólo a los hombres de ciencia, sino también a los escritores.

En la literatura, el vínculo incestuoso se resuelve, a veces, por el suicidio, la muerte provocada por la condenación social o en la completa exclusión y aislamiento de los amantes del mundo que los rodea, como ocurre en el cuento de Thomas Mann, "La sangre de los Walsung". Aquí, el aristócrata Siegmund y su hermana, Sieglinde, estrechan un vínculo que ellos consideran noble y sagrado, y que los excluye de un mundo que desdeñan por su trivialidad.

Con respecto al tema del incesto, Mann es más conocido por una novela, El elegido, que se ubica en la Edad Media. El protagonista, Gregorius, nacido de una unión incestuosa de un hermano y una hermana, es llevado muy lejos para ser educado como sacerdote. A la edad de diecisiete años, regresa por casualidad a su tierra natal y, sin reconocerla, se enamora de su madre. Se casa con ella. Cuando ambos descubren la verdad, él se va a vivir en penitencia durante diecisiete años. Entonces, en Roma, un hombre es visitado por el Cordero Divino quien le revela que el próximo Papa habrá de ser Gregorius; así ocurre. Que un hombre como Gregorius, cargando con el pecado de un doble incesto, sea elegido Papa, en cierto sentido santifica ese tipo de unión. El libro (que se basa en una leyenda del medioevo) sugiere que el destino pecador y sagrado del protagonista son una sola cosa, y que Dios no sólo lo ha elegido como Papa, sino para ser el hijo, el sobrino y el marido de su propia madre. Como en "La sangre de los Walsung", Mann presenta, otra vez, el incesto como un rito sagrado y un destino reservado para los elegidos.

Básicamente, el conocimiento del incesto y no el incesto mismo es lo que fascina y horroriza a la gente. En la literatura del incesto hay tres situaciones principales: a veces los amantes saben, desde el principio, que están emparentados y son, por ende, presa de una horrible culpa. Otros descubren el vínculo familiar justo a tiempo y evaden un destino cruel. Por último, 
acontece que gozan en la inocencia de su felicidad, pero caen en el abismo de la desesperación al enterarse de la verdad.

Parece obvio que el tabú del incesto es algo más que un fenómeno moral o genético. Las razones morales y religiosas se contradicen a sí mismas:

El norteamericano medio, sea hombre o mujer, profesa un rechazo ante la idea de una relación incestuosa -y hasta presentará este repudio instintivo, como base de la prohibición del incesto. Extraña argumentación, cabe anotar, ya que lo que es instintivamente repudiado no deberia ser prohibido. (Levine 1975: 120)

En su libro El erotismo, George Bataille llega a la conclusión de que los tabúes tienen que ver con el juego de los profundos impulsos en los individuos. Pero eso, refuta la teoría sociológica de Claude Lévi-Strauss (los tabúes sólo aparecen entre los hombres, son el resultado de la conciencia social y cultural). Bataille insiste que Lévi-Strauss deja fuera de optica una importante diferencia entre el hombre y la bestia: el erotismo.

Según él, el erotismo surge de una alternancia de fascinación y horror, de afirmación y negación (base del concepto de lo sagrado, vid. Chinchilla, Kattia. 1992. "Mircea Eliade, una clave para la interpretación del pensamiento mítico"). El tabú del incesto es simplemente la forma más extrema y universal del tabú sexual más corriente, como el de la desnudez en público. Y todos los demás tabúes sexuales son funciones del erotismo. Un tabú sexual convierte al objeto prohibido en algo más deseable. Cuanto más violento el deseo, mayor el terror de la violación del tabú.

Esta interpretación de Bataille permite ver a la solterona Amaranta como una de las criaturas más eróticas de Cien años de soledad. Ursula, cerca del fin de vida, aprecia más bien su ternura:

Amaranta, en cambio, cuya dureza de corazón la espantaba, cuya concentrada amargura la amargaba, se le esclareció en el último examen como la mujer más tiema que había existido jamás (...) (García Márquez 1971: 214)

La exaltación hiperbólica del sexo, unida a las insinuaciones incestuosas, convierten esos momentos en la paradojica representación del máximo goce y la tragedia definitiva.

Es a través de estos grandes momentos de liberación que la familia Buendía realiza su predestinación más o menos apócrifa. Y a pesar de que García Márquez presenta el incesto como vehículo de felicidad y a pesar de la insistencia de ciertos socíblogos de que el incesto es un impulso perfectamente natural y comprensible, la presentación de la materia en la novela no ha perdido su fuerza medieval. Visto como centro, como lo oficial, el incesto es una maldición de los Buendía que condena al linaje a su eterna soledad.

\section{El mito de Edipo y su relación con la novela}

En el nacimiento de Edipo hay dos elementos por considerar: la culpa del padre y el intento de filicidio (cosa similar se da en la historia de Paris, hijo de Príamo). Una profecía advirtió que el nacimiento de Edipo pondría en peligro la vida de Layo: este hijo maldito matará a su 
padre y se casará con su madre. En Cien años de soledad. José Arcadio Buendía mata a su amigo, Prudencio Aguilar, y luego tuvo relaciones sexuales, por primera vez, con su esposa Ursula (su prima): era una alianza prohibida, ya que

Tenían [los padres de la pareja] el temor de que aquellos saludables cabos de dos razas secularmente entrecruzadas pasaran por la vergüenza de engendrar iguanas. (García Márquez 1971: 25)

Cuando nace Edipo es mandado a matar, pero en realidad es abandonado; lo recogen unos pastores quienes lo entregan a los reyes de Corinto, que carecían de descendencia. Por tanto, es adoptado por Polibo y Mérope. Edipo no conoce su verdadera identidad. En la novela, hay una adopción (Rebeca) y dos miembros de la familia no conocen su origen: Arcadio, hijo de José Arcadio, y Aureliano Babilonia, hijo de Meme (Renata Remedios).

Al consultar el oráculo de Delfos, por sospechar que no es hijo de sus padres adoptivos, Edipo se entera de la terrible profecía: será un futuro parricida e incestuoso. Abandona Corinto, tratando de eludir su destino, pero llega a Tebas, su auténtica tierra natal. En Cien años de soledad hay varios viajes y otros tantos regresos. Son los que permiten un surgimiento o recrudecimiento de la conducta incestuosa: José Arcadio vuelve de su viaje por el mundo para casarse con Rebeca, su hermana adoptiva (y, por edad, su hija figurada); Aureliano José regresa dispuesto a casarse con Amaranta, su tía (pero madre adoptiva); el último José Arcadio, el seminarista, vuelve de Roma para cultivar mentalmente su incesto nunca realizado con Amaranta, su tía bisabuela; Amaranta Ursula regresa de Bruselas y concreta la unión con su sobrino (y hermano figurado) Aureliano Babilonia.

Edipo vence a la Esfinge, el monstruo hembra que plantea un enigma cuya respuesta es "el hombre" (devora a quienes no lo resuelven). Pero Edipo dilucida el enigma mayor, el de su propio origen y, con ello, su horrendo crimen. La resolución del acertijo de la Esfinge es anterior al incesto, el de su identidad es posterior. En el texto de García Márquez, el acertijo lo constituyen los manuscritos de Melquíades, cuya solución sólo se obtiene después de la consumación del incesto: Aureliano Babilonia conoce su origen y su destino postrero.

Al conocer la verdad, Edipo se perfora los ojos precisamente con un prendedor de Yocasta, permanece errante por un tiempo, pero un oráculo indica que la tierra que diere sepultura a Edipo tendría la bendición de los dioses. El oráculo que lo mancilla y lo convierte en un ente maculado, lo redime y hasta lo santifica, acogiéndolo en una tierra que se volverá bendita. Aureliano Babilonia descubre la verdad, con lo que se destruye Macondo y da fin a la historia ("tale fiction").

Las acciones edípicas destruyen las leyes, el orden natural y el mundo moral, pero posibilitan la edificación de un nuevo mundo sobre los escombros del antiguo. (Ludmer 1974: 27)

Aquí encontramos un basamento para nuestra visión "descentrada" del incesto. Y las palabras de Yocasta, en el Edipo Rey son elocuentes, todos anhelamos regresar a la madre (como el mismo Edipo regresa a la Tellus Mater, pura y santa), esto es el regressus ad uterum: 
Lo mejor es vivir sin preocuparse, cada uno como pueda. Además, ¿por qué angustiarte por bodas con la madre? ¡Muchos las tienen: en sueños se unen maritalmente con sus madres! (Sofocles 1980: 141)

\section{El incesto como plenitud/centro}

El incesto, según Lévi-Strauss, es una de las pocas reglas universales e indica que la sociedad ya se ha formado (donde hay regla hay sociedad). Eludiendo esta regla, sólo dos personajes alcanzan la verdadera felicidad: Amaranta Ursula y Aureliano Babilonia. Y su producto, el cola de cerdo, será el único, de todos los Buendía, engendrado con amor. Ese incesto, esa entrega total, los hace superar la soledad y vivir la felicidad auténtica:

(...) y aquellas evocaciones les revelaron la verdad de que habían sido felices juntos desde que tenían memoria. (García Márquez 1971: 344)

Pero sólo se aprecia que la familia está condenada a cien años de soledad y aparece un "animal mitológico" que pone punto final a la estirpe. ¿Punto final? Eso lo veremos luego. La soledad o aislamiento es el castigo a la conducta habitual de la familia que se entrega al incesto:

La pareja incestuosa es como una familia avara, se aísla automáticamente de este juego que consiste en dar y en recibir, que es, en suma, el núcleo de toda la vida de la tribu; en el cuerpo colectivo se transforma en un miembro muerto o paralizado. (Amau 1975:123)

Toda la historia de Cien años de soledad está dominada por un temor y, al mismo tiempo, una atracción por el incesto. La vocación incestuosa es, como la soledad y la imagen de Melquíades, un cromosoma de los Buendía. El hilo conductor de la obra es ese doble plano: miedo/atracción por el incesto. Cuando el temor se olvida, el incesto se cumple y nace el temido cola de cerdo, una "vergüenza para castigar el pecado cometido". Lévi-Strauss habla que un pariente en matrimonio incestuoso es una "pata de elefante". El precedente de este niño-monstruo se narra, a propósito del matrimonio de Ursula y José Arcadio Buendía:

Una tía de Ursula, casada con un tío de José Arcadio Buendía, tuvo un hijo que pasó toda la vida con unos pantalones englobados y flojos y que murió desangrado después de haber vivido cuarenta y dos años en el más puro estado de virginidad, porque nació y creció con una cola cartilaginosa en forma de tirabuzón y con una escobilla de pelos en la punta. Una cola de cerdo que nunca dejó ver de ninguna mujer, y que le costó la vida cuando un carnicero amigo le hizo el favor de cortársela con una hachuela de destazar. (García Márquez 1971: 25)

Todo Cien años de soledad está dominado por un doble matriarcado: el de Ursula, moral, pues funciona como conciencia familiar; ella es precisamente quier cuida de que ningún Buendía se case con alguien de su misma sangre, atemorizándolos con el hijo cola de cerdo. Y el de Pilar Ternera, sexual, ya que inicia y aconseja en los asuntos amorosos a los Buendía. Pre- 
siden toda la novela y no es coincidencia que ambas rebasen los cien años: son los dos ejes centrales (conciencia y sexualidad).

El complejo edípico de la estirpe se verifica en la interrelación constante en el área semántica de la palabra madre (vid. Valverde, Leticia. 1983. "Ursula, Petra Cotes y Pilar Ternera: una tríada mítica de lo inconsciente colectivo"). Ursula y Pilar Ternera se mezclan y confunden.

\section{El incesto como suplemento/margen: lo críptico}

Según Lois Marie Jaeck, la falta de un referente externo es la responsable del patrón repetitivo de la familia Buendía: la unión entre primos (José Arcadio Buendía y Ursula Iguarán) crea una estructura familiar cerrada que se vuelve sobre sí misma. En las generaciones sucesivas, se repite el patrón inicial, incestuoso, cerrado: José Arcadio y Rebeca (quien se supone que es una prima lejana); Pilar Temera es la madre de dos niños cuyos padres son hermanos (José Arcadio es el padre de Arcadio y el coronel Aureliano Buendía lo es de Aureliano José); Amaranta tiende hacia el incesto con su sobrino Aureliano José y su sobrino bisnieto José Arcadio, el seminarista; finalmente, la consabida unión entre Amaranta Ursula y Aureliano Babilonia. Sin embargo, hay cuatro elementos exógenos: Pilar Ternera, Santa Sofía de la Piedad, Fernanda del Carpio y Mauricio Babilonia. Es Pilar Ternera, como ya hemos citado, quien afirma que la familia Buendía es una cadena de repeticiones, como una especie de rueda giratoria. Ursula también llega a tal conclusión:

En la larga historia de la familia, la tenaz repetición de los nombres le había permitido sacar conclusiones que le parecían terminantes. Mientras los Aurelianos eran retraídos, pero de mentalidad lúcida, los José Arcadios eran impulsivos y emprendedores, pero estaban marcados por un signo trágico. Los únicos casos de clasificación imposible eran los de José Arcadio Segundo y Aureliano Segundo [se presume una inversión de nombres en sus juegos infantiles para confundir a los demás]. (García Márquez 1971: 159)

El incesto entre Amaranta Ursula y Aureliano Babilonia participa del simbolismo mandálico, en el sentido de representar la unión armónica de la psique consciente, el yo (Aureliano Babilonia) y el inconsciente (Amaranta Ursula). La penúltima generación de los Buendía supera el temor hereditario de la estirpe, dejando de un lado la prohibición familiar contra el incesto, alcanzan pues el sí mismo (selbst), especialmente con el nacimiento del cola de cerdo, aspecto éste que lo distingue de los demás miembros de su familia: un ser híbrido que integra plenamente la psique consciente, el yo, pero instintiva e irracional, representada por la cola de cerdo. Es el filius hermaphroditus, pues armoniza los aspectos masculinos y femeninos de la psique, en lo que ahondaremos luego. Mientras tanto veamos el carácter especial de este incesto:

A medida que avanzaba el embarazo se iban convirtiendo en un ser único (...) (García Márquez 1971: 345)

La natividad del último Aureliano, el niño cola de porcino, el único engendrado con amor en cien años, nos es descrita así: 
Un domingo a las seis de la tarde, Amaranta Ursula sintio los apremios del parto. La sonriente comadrona de las muchachitas que se acostaban por hambre la hizo subir en la mesa del comedor, se le acaballó en el vientre, y la maltrató con los galopes cerriles hasta que sus gritos fueron acallados por los berridos de un varón formidable. A través de las lágrimas, Amaranta Ursula vio que era una Buendía de los grandes, macizo y voluntarioso como los José Arcadios, con los ojos abiertos y clarividentes de los Aurelianos, y predispuesto para empezar la estirpe otra vez por el principio y purificarla de sus vicios perniciosos y su vocación solitaria, porque era el único que en un siglo había sido engendrado con amor. (García Márquez 1971: 346)

Nótese la síntesis de los rasgos familiares. En efecto, el último vástago de la estirpe encarna el filius macrocosmi, conocido también como Salvator o Deus terrestris, tres designaciones para el lapis philosophorum de la alquimia, una especie de ser místico comparable con el Antropos de los gnósticos, el hombre divino original:

(...) el último Aureliano representa la plenitud humana, un ser total que existió antes que el hombre y que es asimismo, su meta final. (Torres Caballero 1990: 146)

Hablemos un poco del mandala y el uróboros, imágenes homólogas del incesto, como una totalidad e integración. El mandala es el círculo tántrico, representa al cosmos en su relación con las potencias divinas y, psicológicamente, la plenitud de la psique o el sí mismo. Esto último no refleja la paradoja derridiana del centro y el margen (la "plenitud" y el suplemento). El mandala se asemeja al laberinto, pues un modelo similar se traza sobre el suelo para los ritos de la peregrinación, en las catedrales europeas (la de Chratres, en Francia, es un excelente ejemplo, con sus doscientos metros para que los fieles los recorran de rodillas). El acceso al laberinto y la salida de éste es símbolo de la muerte y resurrección espirituales (ir al interior de sí mismo, hacia donde reside lo más misterioso y desconocido del ser). Aureliano Babilonia lo descubre:

Amaranta Ursula no era su hermana, sino su tía, y que Francis Drake había asaltado Riohacha solamente para que ellos pudieran buscarse por los laberintos más intrincados de la sangre, hasta engendrar al animal mitológico que había de poner término a la estirpe. (García Márquez 1971: 350) (El subrayado es nuestro)

La estructura urobórica de Cien años de soledad la convierte en símbolo de un opus alquímico que paulatinamente va transformando la psique de la estirpe Buendía. El uróboros, el dragón que se muerde la cola, símbolo de la autosuficiencia tanto paradisíaca como postapocalíptica. La consecución de dicha trascendencia psíquica resulta inminente hacia las postrimerías de la novela al conjugarse la consumación de tres motivos recurrentes: la cópula incestuosa, el nacimiento del vástago con cola de cerdo y el desciframiento de los pergaminos.

El uróboros, para el psicólogo alemán Erich Neumann, es la imagen de la perfección que se circunda a sí misma, la serpiente primordial, extraída de la mitología egipcia, es el auto-procreador del comienzo de las cosas, el dragón que se muerde la cola. En las tierras del Nilo decían: 
Draco interfecit se ipsum, maritat se ipsum, impraegnat se ipsum (...) Ego sum qui copulavi pugno meo, libidinem sentivi in umbra mea semen cecidit (?) (sic) e meo ipsius ore. (Müller 1990: 84)

El éxito de Aureliano Babilonia, al descifrar los pergaminos, se explica, en términos alquímicos y psíquicos, primeramente, por su carácter de hombre medieval y, en segundo término, porque, dejando a un lado la prohibición familiar, consuma el incesto con su tía Amaranta Ursula: alcanza la integración armónica de la psique consciente y el inconsciente, el sí mismo o huevo filosófico de la alquimia, como lo afirma Torres Caballero (1990: 144).

El primer capítulo contiene, asimismo, el germen apocalíptico de la revelación (el hie1o). Dicha indicación debe asociarse con la visión de Melquíades de "una ciudad luminosa, con grandes casas de vidrio" (García Márquez 1971: 53), la nueva Jerusalén, en la que no queda rastro de la estirpe Buendía. Para nosotros, se alude a un nuevo ciclo de la humanidad en cual el individuo habrá superado la soledad o falta de amor, al lograr la madurez psíquica:

La madurez psíquica comportaría la asimilación del inconsciente dentro de un balance psíquico armónico y pleno, cuya representación simbólica sería el uróboros como mandala. (Torres Caballero 1990: 144)

El hielo es el símbolo de la conexión de lo formal y lo informal, como el agua. En psicología, es la división rígida de la consciencia y lo inconsciente, por esto, al inicio de la obra, es el elemento primario y revelador y al final sólo es un espejismo, pero ya integrador, pues se ha abolido la escisión y hemos regresado al estado previo, a la génesis de la conciencia. Veamos:

José Arcadio Buendía soñó esa noche que en aquel lugar se levantaba una ciudad ruidosa con casas de paredes de espejo. Preguntó qué ciudad era aquella, y le contestaron con un nombre que nunca había oído, que no tenía significado alguno, pero que tuvo en el sueño una resonancia sobrenatural: Macondo. (...) ... no logró descifrar el sueño de las casas con paredes de espejos hasta el día en que conoció el hielo. (García Márquez 1971: 28)

No serán casas de vidrio [le replicó a Melquíades] sino de hielo, como lo soñé (...) (García Márquez 1971: 53)

(...) pues está previsto que la ciudad de los espejos (o los espejismos) sería arrasada por el viento y desterrada de la memoria de los hombres en el instante en que Aureliano Babilonia acabara de descifrar los pergaminos (...) (García Márquez 1971: 351)

Si la esencia del hielo presenta un mandala potencial, la escena en que Aureliano Babilonia alcanza la revelación contiene varios elementos que apuntan hacia la plenitud "mandálica". Se cierra el ciclo "urobórico", comenzado con la imagen onírica del patriarca y luego con su imagen real al conocer el hielo. Varios elementos han sido vistos como posibles mandalas: los discos anaranjados que cruzan el cielo, el incesto, los pergaminos y el cola de cerdo.

El incesto implica la exaltación de la propia esencia, el descubrimiento y la preservación del yo más profundo. Cuando Melquíades le dice a José Arcadio Buendía que en un futuro no habrá ningún descendiente suyo, el patriarca lo increpa al instante: "siempre habrá un Buen- 
día por los siglos de los siglos" (García Márquez 1971: 53). La concreción del incesto ratifica lo anterior, pues se instalarán en un tiempo mítico (eis aionas, per saecula saeculorum) y, por ende, en una nueva dimensión, que no es de este mundo, ¿será la nueva Jerusalén del Libro de Revelaciones? El incesto es una regresión interior, un regressus ad uterum (tía-sobrino/madre-hijo), un regreso al paraíso edénico.

Es una vía hacia la individuación o selbst (equilibrio psíquico): unión de la esencia de uno mismo, en un plano distinto del que se vive diariamente:

Perdieron el sentido de la realidad, la noción del tiempo, el ritmo de los hábitos cotidianos. (García Márquez 1971: 341)

A medida que avanzaba el embarazo se iban convirtiendo en un ser único, se integraban cada vez más en la soledad... (García Márquez 1971: 345)

Como nos cuenta Hesíodo, Gea da origen a Uranos, su compañero e hijo, sin el concurso del elemento masculino, lo que en cierta medida nos señala la virginidad de su parte. Es una hierogamia cósmica o matrimonio sagrado del Cielo y la Tierra. En la novela, hay dos uniones vitales: José Arcadio Buendía-Ursula Iguarán (primos/hermano-hermana/Sol-Luna) y Aureliano Babilonia-Amaranta Ursula Buendía (sobrino-tía/hijo-madre/Cielo-Tierra). La primera es la arquetípica o ejemplar y la última es la definitiva, su producto es un niño con cola de cerdo. Es abandonado a su suerte y finalmente, devorado por las hormigas, como una especie de niño solar, el cual es observado en algunas mitologías. Este último Aureliano es conducido a la oquedad telúrica, como el astro rey es "tragado" en el ocaso:

Era un pellejo hinchado y reseco, que todas las hormigas del mundo iban arrastrando trabajosamente hacia sus madrigueras por el sendero de piedras. (García Márquez 1971: 349) (El subrayado es nuestro)

Nótense los apelativos en los cuales pueden apreciarse las facultades solares y, especialmente, su tránsito diario hacia el oeste, visto en la figura de madriguera, y su lucha con los "monstruos" ctónicos (las hormigas), que logran vecerlo temporalmente.

Ahora bien, pese a su parentesco, Amaranta Ursula y Aureliano Babilonia crecieron juntos como hermanos y así cayeron, por un momento, en la cuenta de su incesto, luego de la fornicación:

(...) aquella suposición les produjo en el alma una torcedura de horror.

Atormentado por la certidumbre de que era hermano de su mujer, Aureliano se dio una escapada a la casa cural para buscar en los archivos rezumantes y apolillados alguna pista cierta de su filiación. (García Márquez 1971: 344)

Ad de Vries coincide con Carl Gustav Jung, al postular el incesto como individuación:

(...) al longing for union with the essence of one's own self, for Individuation; especially in the sister-brother relation, also in modern novels. (Vries 1984: 269) (El subrayado es nuestro) 
La base fundamental del incesto no es sólo la cohabitación, sino la idea de volver a ser niño, de introducirse en la madre (regressus ad uterum) para ser parido de nuevo por ella. Tal eventualidad es observada en José Arcadio, al unirse con Pilar Ternera:

Quería estar con ella en todo momento, quería que fuera su madre... (García Márquez 1971: 29)

(...) donde trataba de acordarse del rostro de ella y se encontraba con el rostro de Ursula, confusamente consciente de que estaba haciendo algo que desde hacía mucho tiempo deseaba que se pudiera hacer, pero que-nunca se había imaginado que en realidad se pudiera hacer, sin saber cómo lo estaba haciendo (...) (García Márquez 1971: 31)

En la segunda cita puede apreciarse la confusión perifrástica (poder/hacer), clave de la dubitación incestuosa. Más tarde, José Arcadio, cuando se une con Rebeca, se solaza al llamarla "hermanita". El coronel Aureliano Buendía y Pilar Ternera repiten el esquema, cuando éste evoca a la pequeña Remedios Moscote:

Buscó a Aureliano en la oscuridad, le puso la mano en el vientre y lo besó en el cuello con una ternura maternal. Mi pobre niñito, murmuró. Aureliano se estremeció. (García Márquez 1971: 65)

Arcadio, el hijo de José Arcadio, se sentía atraído pasionalmente por su madre Pilar Ternera, aunque desconocía su origen:

Arcadio la agarró por la muñeca y trató de meterla en la hamaca. "No puedo, no puedo", dijo Pilar Ternera, horrorizada. "No te imaginas cómo quisiera complacerte, pero Dios es testigo que no puedo." (García Márquez 1971: 101)

Aureliano José, hijo del coronel Aureliano Buendía y Pilar Ternera, se obsesiona por su tía Amaranta:

Se consolaba con su abrupta soledad, de su adolescencia prematura, con mujeres olorosas a flores muertas que él idealizaba en las tinieblas y las convertía en Amaranta mediante ansiosos esfuerzos de imaginación. (García Márquez 1971: 127)

Amaranta también propicia una pasión incestuosa y mortal en José Arcadio, el seminarista, a pesar de su tendencia homosexual y pederasta:

[Aureliano Babilonia](...) buscó a José Arcadio por toda la casa, y lo encontró flotando en los espejos perfumados de la alberca, enorme y tumefacto, y todavía pensando en Amaranta. (García Márquez 1971: 317)

Con base en Jung, el incesto no busca el coito sino el renacimiento, especialmente de tipo óntico. Y algo de esto hay en la última oración de la novela: "las estirpes condenadas a cien años de soledad no tenían una segunda oportunidad sobre la tierra." San Juan, en el Apocalipsis $(21,8)$, dice que sólo los pecadores irán a un lago de fuego y azufre, y esa será su segunda 
muerte. Por tanto, hemos visto que el niño cola de cerdo fue el único engendrado con amor y, así, se ha abolido la soledad, el sello execrable de la estirpe Buendía. Por ende, a nuestro juicio, no tenían una segunda oportunidad, porque no la necesitaban, vendría a ser una segunda muerte, sólo para quienes no hayan alcanzado el estado de pureza y perfección (recuérdese el carácter purificador y detersivo del fuego y el azufre). El último Aureliano es un ente mítico que los hará transitar por el sendero feliz de la individuación espiritual o psíquica. A lo largo del texto se vislumbra este ideal, como ya lo anotamos, mediante el hielo, el mandala (los discos anaranjados) y el uroboros. Se concreta esa vía con el nacimiento-muerte (terrena) del niño cola de cerdo.

\section{El último Aureliano, el cola de cerdo}

Antes de abordar este tema, hay dos datos curiosos que merecen ser citados. Primero, Susanne L. Levine (1975: 21) afirma que, luego de la aparición de Cien años de soledad, apareció un hombre de Barranquilla, el cual, según contó en una carta a un periódico, tenía cola de cerdo, como el último de los Buendía. En segundo término, Sultana Wahnón (1994: 100) indica que el hijo con cola de cerdo representa la imagen de todos los miedos que una familia de judíos conversos, en el Nuevo Mundo, podía albergar, acerca del futuro de su descendencia. Sería una tara. Se pensaba que los judíos tenían un muñón, una especie de rabo, al final de las vértebras, como los demonios. Datos curiosos.

Si al final del laberinto minoico se encontraba un híbrido de hombre y toro, en el de García Márquez encontramos, al principio y al final -en la imagen de circularidad infinita que privilegia la lectura habitual de Cien años de soledad - un híbrido de hombre y cerdo:

El cola de cerdo es el monstruo híbrido que nos esperaba al final del laberinto, es decir, la solución al enigma de la sangre de los Buendía. (Wahnón 1994: 101)

En el texto se le llama "animal mitológico" y, por su naturaleza, responde a la definición de monstruo. Ursula es quien "salvaguarda" a la estirpe para que no nazca el ente. Con su muerte, se olvidan sus preceptos y aparece el último Aureliano. Veamos los que nos dice la novela:

Una tía de Ursula, casada con un tío de José Arcadio, tuvo un hijo (...) con una cola cartilaginosa en forma de tirabuzón y con una escobilla de pelos en la punta. Una cola de cerdo... (García Márquez 1971: 25)

[recomendaciones de Ursula](...) para que cuidaran de que ningún Buendía fuera a casarse con alguien de su misma sangre, porque nacían los hijos cola de puerco. (García Márquez 1971: 291)

S6́lo cuando lo voltearon [al último Aureliano] boca abajo se dieron cuenta de que tenía algo más que el resto de los hombres, y se inclinaron para examinarlo. Era una cola de cerdo.

No se alarmaron, Aureliano y Amaranta Ursula no conocían el precedente familiar, ni recordaban las pavorosas admoniciones de Ursula (...) (García Márquez 1971: 347) 
Como monstruo, es señal de lo sagrado (que repele y causa terror o desgracia, en este caso la muerte de su madre), la fuerza irracional, lo informe, lo caótico (massa confusa), lo tenebroso, lo abismal. Estas valencias responden al regressus ad uterum: la noche primordial, el caos, que da paso al cosmos, una imagen de lo inconsciente, potencia pre-formal.

Analicemos la cola. Por su forma, obviamente nos remite al falo y esta relación la establece Ursula con su hijo José Arcadio:

Una noche Ursula entró en el cuarto cuando él se quitaba la ropa para dormir, y experimentó un confuso sentimiento de vergüenza y piedad: era el primer hombre que veía desnudo, después de su esposo, y estaba tan bien equipado para la vida, que le pareció anormal. (...) Pensaba que su desproporción era algo tan desnaturalizado como la cola de cerdo del primo. (García Márquez 1971:29)

La cola es el símbolo del poder animal. Entonces esta infeliz criatura es híbrida: hombre y animal, a la vez, pero sin ser ninguno de los dos totalmente. Decimos infeliz, pues lo que se sale del patrón natural o "normal", no pertenece a estas coordenadas terrenales y está hecha para el laberinto o la reclusión. No obstante, dejemos que esta cita de Vladimir Nabokov nos motive y anime:

Bendigamos al monstruo, pues en la evolución natural de los seres el mono no se habría convertido en hombre si no hubiese aparecido un monstruo en la familia. (López 1986: 389)

¿Por qué cola de cerdo? Este mamífero omnívoro se asimila a las tendencias oscuras y negativas. Pero en otras culturas, no influidas por el judaísmo, cristianismo e islamismo en su porcofobia, es el ancestro mítico, rasgo muy pertinente en nuestras consideraciones, pues sería una especie de animal totémico para la familia Buendía: se manifiesta en la génesis del clan y en su escatología.

En Occidente se ha visto como imagen maternal: interviene en la fundación de ciudad latina de Alba Longa; en Eleusis, es familiar a la diosa Deméter y a sus iniciados. Cosa curiosa, en griego, cerdo (choîros) se relaciona, semánticamente, con el órgano sexual de la mujer. Vemos en todo esto, una figura simbólica de la madre, es decir, un retorno mítico a ella, en procura del resurgimiento ontológico.

Las hormigas, que lo devoran y lo conducen al antro telúrico, figura vaginal, son un elemento digno de mención. Su pequeñez evoca lo infinito de la divinidad, semejante a estructura sub-atómica: vida organizada en "sociedad", en orden, en cosmos. Son animales telúricos, dada su cercanía con la tierra, de ahí sus atributos adivinatorios y proféticos, derivaciones de su facultad primaria:la sabiduría. Entre los indios apalai (Sudamérica), sus picaduras son consideradas medicinales y curativas (Frazer 1982: 237).

En algunas mitologías africanas (dogon y bambara) el sexo de la tierra es un hormiguero, retrato cosmogónico. Si pensamos en el texto de García Márquez, todas las hormigas del mundo cargan con el niño; esta figura nos sugiere el asalto de los espermatozoides hacia el óvulo (habiendo algo de lo femenino en la cola de cerdo, recuérdese además que este principio es bisexual, como lo señala Eliade), para dar inicio a la vida y repetir el gesto primordial de la 
creación universal: óvulo y espermatozoide se unen, se fusionan en el útero ignoto y oscuro (hormiguero), pero mueren en su naturaleza particular y hacen posible el tránsito a un nuevo estadio (la mórula). Vida y muerte se conjugan, se alternan, concretando el enigma ancestral del hombre.

\section{Conclusiones}

Condenados a cien años de soledad. El número cien indica un microcosmos en un macrocosmos, que tiende a individualizar a una persona, un grupo o una realidad dentro de un conjunto. Se asimila a la perfección, idea coherente con lo expuesto acerca de las nociones de tiempo e incesto. ¿Y la soledad?

La soledad referida en el título emerge como un leitmotiv y el principal tema, la sencillez irracional de los personajes y la limitada capacidad de amar. La soledad es un obstáculo aparente para la individuación, mas se presenta como un preludio: es la vivencia del sabio (tipo Aureliano Babilonia) quien es autártico y aislado amén de su perfección. Cosa notable, es fácil pensar que la autosuficiencia de la soledad se presenta hasta en la presentación de la novela, por parte de la casa editorial Sudamericana, en las ediciones de 1967 a 1972, con la "E" invertida en la palabra soledad, en la portada del libro. Pero esta es una postura ideal, aunque el texto nos revela cuán inútil es el conocimiento de Aureliano en las cosas cotidianas (profanas y sin importancia). Lo que en parte nos recuerda el pensar de Aristóteles con respecto a la ciencia (el saber por el saber): cuanto más inútil sea el conocimiento, ese es el superior.

En la novela del colombiano García Márquez, la soledad es la imposibilidad de comunicación, sello insondable y casi patológico de la estirpe:

[Con respecto a los diecisiete Aurelianos] Llevaron niños de todas las edades, de todos los colores, pero todos varones, y todos con un aire de soledad que no permitía poner en duda su parentesco. (García Márquez 1971: 133) (El subrayado es nuestro)

Extraviado [el coronel Aureliano Buendía] en la soledad de su inmenso poder, empezó a perder el rumbo. (Garcîa Márquez 1971: 146) (El subrayado es nuestro)

... José Arcadio Segundo se volvió óseo como el coronel, y lo único que conservaron [él y su hermano gemelo] en común fue el aire solitario de la familia. (García Márquez 1971: 160) (El subrayado es nuestro)

... el coronel Aureliano Buendía apenas comprendió que el secreto de una buena vejez no es otra cosa que un pacto honrado con la soledad. (García Márquez 1971: 174) (El subrayado es nuestro)

... Amaranta pensaba en Rebeca, porque la soledad le había seleccionado los recuerdos. (García Márquez 1971: 190) (El subrayado es nuestro)

... [Ursula] en la impenetrable soledad de la decrepitud... (García Márquez 1971: 213) (El subrayado es nuestro) 
... la amarga soledad de las parrandas [de Aureliano Segundo].2 (García Márquez 1971: 232) (El subrayado es nuestro)

Aquel acercamiento entre dos solitarios [Aureliano Babilonia y José Arcadio, el seminarista] de la misma sangre estaba muy lejos de la amistad, pero les permitió a ambos sobrellevar mejor la insondable soledad que al mismo tiempo los separaba y los unía. (Garć́a Márquez 1971: 316) (El subrayado es nuestro)

Pero Amaranta Ursula y Aureliano Babilonia van rompiendo el esquema: "estaban tan identificados que preferían la muerte a la separación." (García Márquez 1971: 342). Recuérdese que el último Aureliano, al ser engendrado con amor, rompe la barrera impuesta por la soledad.

El amor es un sentimiento desconocido para los Buendía, anteriores a la sexta generación. El amor es la unión de los opuestos o coincidencia de los contrarios, la pulsión fundamental del ser. El acto, en lo biológico, expresa el anhelo de morir en lo anhelado, de disolverse en lo disuelto. Observémoslo en el texto, a propósito de la coyunda de Amaranta Ursula y Aureliano Babilonia:

Una conmoción descomunal la inmovilizó en su centro de gravedad, la sembró en su sitio y su voluntad defensiva fue demolida por la ansiedad irresistible de descubrir qué eran los silbos anaranjados y los globos invisibles que la esperaban al otro lado de la muerte. Apenas tuvo tiempo de estirar la mano y buscar a ciegas la toalla, y meterse una mordaza entre los dientes, para que no se le salieran los chillidos de gata que ya le estaban desgarrando las entrañas. (García Márquez 1971: 335)

¿Qué razón tenía Unamuno cuando afirmaba que el orgasmo es una pequeña muerte!

Lo tabú, lo exorbitante, lo marginal (por ser maculado o mancillado), la prohibición son consagrados, en la mentalidad mítico-religiosa:

Todo lo que es ajeno o contrario al orden natural, un prodigio, una calamidad pública, una desgracia extraordinaria, un pecado contra la ley natural, un incesto. (Eliade 1981: 39)

En Cien años de soledad, el centro, la matriarca es Ursula Iguarán, quien impone la norma prohibitiva contra el incesto. El centro, entendido como plenitud, no es tal sin el margen o suplemento (alternancia entre el espacio oficial y el carnalavesco, la fuerza centrípeta y la fuerza centrifuga). Con su deceso, se traspasa el límite y se concreta el temido y repudiado incesto. Jacques Derrida (1977: 9) nos dice que el límite siempre está presente para cometer el exceso, la transgresión (concepto análogo al de la hybris griega). ¿Será que el límite existe siempre para ser traspasado, como le ocurriera a Remo? Se impone la relación adentro/afuera, centro/margen y es tarea del desconstruccionismo moverse en ambos planos, al evidenciar que el margen, lo prohibido en su lado críptico, es lo realmente importante es esta estrategia de lectura: un incesto mítico/místico de calidades liberadoras e integradoras. Mutatis mutandis, el mismo García Márquez había revelado que, Cien años de soledad había sido hecha para exponer el tema del incesto, como un pre-texto (Palencia-Roth 1983: 96). Puesto que todo centro es "descentrable", este margen/suplemento se ha transformado en centro/plenitud (inversión de la jerarquía). 
Hemos explicitado lo que se disimula, se margina, se prohibe, lo que se ha instalado, in illo tempore, en lo inconsciente colectivo. Así como no existe el centro pleno, no existe el significado absoluto, gracias al juego del decir y el querer decir. Así esta nueva lectura (que llamanos margen, porque no se encuentra a la luz, porque no es evidente) no se aprecia sin tomar en cuenta la lectura "tradicional" (el centro/ la plenitud). El querer decir es un vacío, una ausencia, una virtualidad, que a partir de la lógica del suplemento, se vuelve plenitud, a pesar de su marginalidad. Hemos detonado una "bomba", revelando una ruptura textual: el incesto es liberador y no castigo, en un intento más por descifrar el rompecabezas.

Un tema como el del incesto es exorbitante y peligroso, su prohibición nace con la suplementaridad (Derrida 1986: 333). Antes de la fiesta (en el espacio carnavalesco, mítico, universal, orgiástico y caótico) no había "incesto", pues no había prohibición expresa para ello. Luego de la fiesta, hay incesto, amén del límite que se impone, aparece el espacio oficial y la sociedad ordenada y organizada, a lo Lévi-Strauss, con sus reglas, normas, leyes.

La parusía del niño cola de cerdo, parafraseando el discurso cristiano, es la escatología de la estirpe, que da paso a la reunión con la deidad (no vuelve a la tierra, en una segunda muerte) o con la vivencia de un estado de equilibrio. ¡Claro no son ideas derridianas!:

La parusía del Señor es el fin de la historia humana; pero no es posible entenderla como si fuese el romper de un nuevo mundo en continuación cronológica de un tiempo histórico que se desarrolló hasta el fin. (...) Todo paso de la vida terrena al "tiempo glorificado" [mítico] es una ruptura posible solamente gracias a la fuerza transformadora de Dios. (Libânio 1985: 219)

En el milenarismo, el personaje mesiánico, liberador, se identifica con el héroe cultual o el antepasado mítico cuyo retorno se esperaba (y se espera, en el contexto cristiano): el cola de cerdo. Su llegada equivale a una reactualización de los tiempos míticos del origen y una recreación del mundo; en nuestro caso, una liberación de la soledad y la coniuctio psíquica: como la muerte humana, se destruye lo carnal (material), pero para dar paso al alma (lo espiritual), la cual obtendrá la eternidad anhelada, junto a la divinidad. Recordemos, por un momento, la primera estrofa de "El Romance A mis soledades voy" de Lope de Vega:
A mis soledades voy,
De mis soledades vengo,
Porque andar conmigo
Me bastan mis pensamientos.
¡No sé qué tiene la aldea
donde vivo y donde muero,
Que con venir de mí mismo
No puedo venir más lejos!
Ni estoy bien ni mal conmigo;
Mas dice mi entendimiento
Que un hombre que todo es alma
Está cautivo es su cuerpo. 
El último Aureliano, el "fatídico" cola de cerdo, pertenece a la sétima generación de la familia. El número siete implica un cambio después de un ciclo consumado (como "el año viejo", o el efímero mundo del Macondo post-diluviano), es una renovación positiva. Aspecto que hemos venido sosteniendo: ¡Qué mejor que lograr una integración psíquica y una liberación del estigma de la soledad!

Siete son los días de la semana, siete los planetas de nuestro sistema solar, siete los niveles celestes, siete los ojos de Dios según Zacarfas, siete las cabezas de Satanás según San Juan, siete los pétalos de la rosa, siete las jerarquías angélicas, siete los colores del arco iris, siete las Hespérides, siete los metales de la escala mitraica, siete las puertas de Tebas, siete las colinas de Roma, siete los hijos y siete las hijas de Níobe, siete los peldaños de la escalera de los masones escoceses (Kadosh), siete las notas musicales, siete las cuerdas de la lira, siete los emblemas del Buda, siete los brazos del candelabro sagrado de los hebreos, siete las circunvalaciones de la Meca. Es un número mágico.

El cuatro es el número de la Tierra y de la mujer, el tres es el del Cielo y del hombre, por lo que el siete es la unión (suma) de los principios femenino y masculino. En su calidad de ser diferente, excepcional, exorbitante, el monstruo tenido por Ursula, el "animal mitológico", al ser el último y el sétimo, es el andrógino, que permitirá y dará acceso al nuevo status óntico, como lo pensaron los alquimistas medievales (vid. Chinchilla, Kattia. 1994. "José Arcadio Buendía y la lucha demoníaca: hacia una valoración mística de la alquimia en el Rosarium Philosophorum de 1550").

El patriarca, José Arcadio Buendía, funda Macondo y se une, en hierogamia, con su consorte, Ursula Iguarán, la matriarca de la especie, empero no logran la integración ni la felicidad marital. Cuando su esposo cae preso de sus propios ensueños, hasta llegar a la locura, ella asume notoriamente las riendas de la casa, siendo la figura dominante, el eje del sistema planetario de los Buendía (García Márquez 1971: 225). Mas no se siente satisfecha con su obra, al afirmar que es Rebeca (elemento exógeno y, en definitiva, marginada por su hybris, ante los ojos de la "mater" familias), quien expresaba mejor lo que ella habría deseado para los suyos:

... Rebeca, la que nunca se alimentó de su leche sino de la tierra y la cal de las paredes, la que no llevó en la venas sangre de sus venas sino la sangre desconocida de los desconocidos cuyos huesos seguían cloqueando en la tumba, Rebeca, la del corazón impaciente, la del vientre desaforado, era la única que tuvo la valentía sin frenos que Ursula había deseado para su estirpe. (García Márquez 1971: 215)

Veamos otro ejemplo de su disconformidad:

... Ursula se preguntaba si no era preferible acostarse de una vez en la sepultura y que le echaran la tierra encima, y le preguntaba a Dios, sin miedo, si de verdad creía que la gente estaba hecha de fierro para soportar tantas penas y mortificaciones (...) y [para] sacarse del corazón los infinitos montones de malas palabras que había tenido que atragantarse en todo un siglo de conformidad. (García Márquez 1971: 216)

José Arcadio Buendía es atado, hasta su muerte, al árbol de castaño, por su estado de enajenación, primero violenta, después dócil (García Márquez 1971: 73-74). En la sentencia epigráfica de los pergaminos de Melquíades, este patriarca y el niño cola de cerdo coexisten como el alfa y la omega: 
... y vio [Aureliano Babilonia] el epígrafe de los pergaminos perfectamente ordenado en el tiempo y el espacio de los hombres: El primero de la estirpe está amarrado en un árbol y al último se lo están comiendo las hormigas. (García Márquez 1971: 349)

A través de la novela, se habla repetidamente del "castaño", pero al final de "árbol", en un sentido más general y hasta vago. El castaño es la imagen de la castidad, de la pureza, lo que se relaciona con el estado de inocencia del niño monstruo. El árbol se relaciona con la vida (igual que el hormiguero) en perpetua evolución. Es considerado antepasado mítico ("el primero de la estirpe"), como lo es el cerdo entre los Buendía (el último Aureliano). Pese a su obvio aspecto fálico, el árbol se asimila a la madre: fuerza creadora y captadora, nutricia y devoradora (igual que las hormigas). Así las cosas, hay rasgos de bisexualidad en el árbol, por lo que Jung afirma que:

... el árbol simboliza el proceso de individuación que da una lección a nuestro miope ego. (Jung 1974: 163)

Ad de Vries (1984:474) ve en él una imago matris, en la cual el héroe (José Arcadio Buendía-fundador-loco-inocente/último Aureliano-niño-inocente, ambos pueden ser vistos como el puer aeternus) llega a la coniuctio:

hero/gods are incorporated into the maternal tree-trunk (e.g. Osiris into cedar, Adonis into the myrtle) (...) Goddesses turned into trees themselves.

Hemos llegado a una palabra común y clave: madre. En términos de Bajtín, dos voces (esquemas) han confluido en una misma voz. Con la abolición (destrucción) del tiempo y el espacio profanos, la estirpe transita hacia una nueva dimensión óntica, se ha liberado de los onerosos cien años de soledad y no necesitan volver a la tierra nuevamente, ya que se han integrado, en lo psíquico, en el terreno no-oficial (mítico-camavalesco), pues allí no existen los tabúes ni las transgresiones, ante la carestía de la alternancia y oposición radical de los centros "plenos" y los márgenes. Torres Caballero (1990: 139) señala el antagonismo entre la conciencia y lo inconsciente:

Los Buendía son desterrados "de la memoria de los hombres" en el sentido de representar una conciencia colectiva que ha sido superada. Los repetidos fracasos de los Buendía son relegados al inconsciente colectivo de una nueva estirpe, desde cuyas capas psíquicas profundas la sabiduría allí contenida puede hacerse accesible en las circunstancias apropiadas.

Heráclito decía que son comunes el principio y el fin en la circunferencia del círculo (frag. 103) y que el camino de las hélices del batán, recto y curvo, es uno y el mismo (frag. 59). Las hélices del batán realizan un doble movimiento: uno recto, hacia arriba, y otro circular. Observando la naturaleza, al morir sólo comenzamos o continuamos el ciclo constante de la vida y de la muerte: nada muere definitivamente. Y si seguimos cavilando, a propósito de las características de la energía, queda aún más claro: la energía no se crea ni se destruye, se transforma. Para concluir, nada mejor que transcribir el poema del poeta ramonense, Lisímaco Chavarría, "Espigas y azucenas": 
La muerte es un matiz de la existencia, morir es florecer en otra forma; la caduca materia se transforma en ser nuevo, en rosales o en esencia.

La vejez es la humana inconsistencia que sometida a la inflexible norma de Natura, se rompe y se deforma en átomos, en luz o en florescencia.

¿Por qué miedo a la muerte? No lo acierto, si de todo placer triunfan las penas, las cuales finan cuando el ser ha muerto.

La vida se desciñe sus cadenas y en la huesa, en el carmen y en el huerto, la carne se hace espigas y azucenas.

\section{Cuadro 1}

Historia de macondo - Los buendia

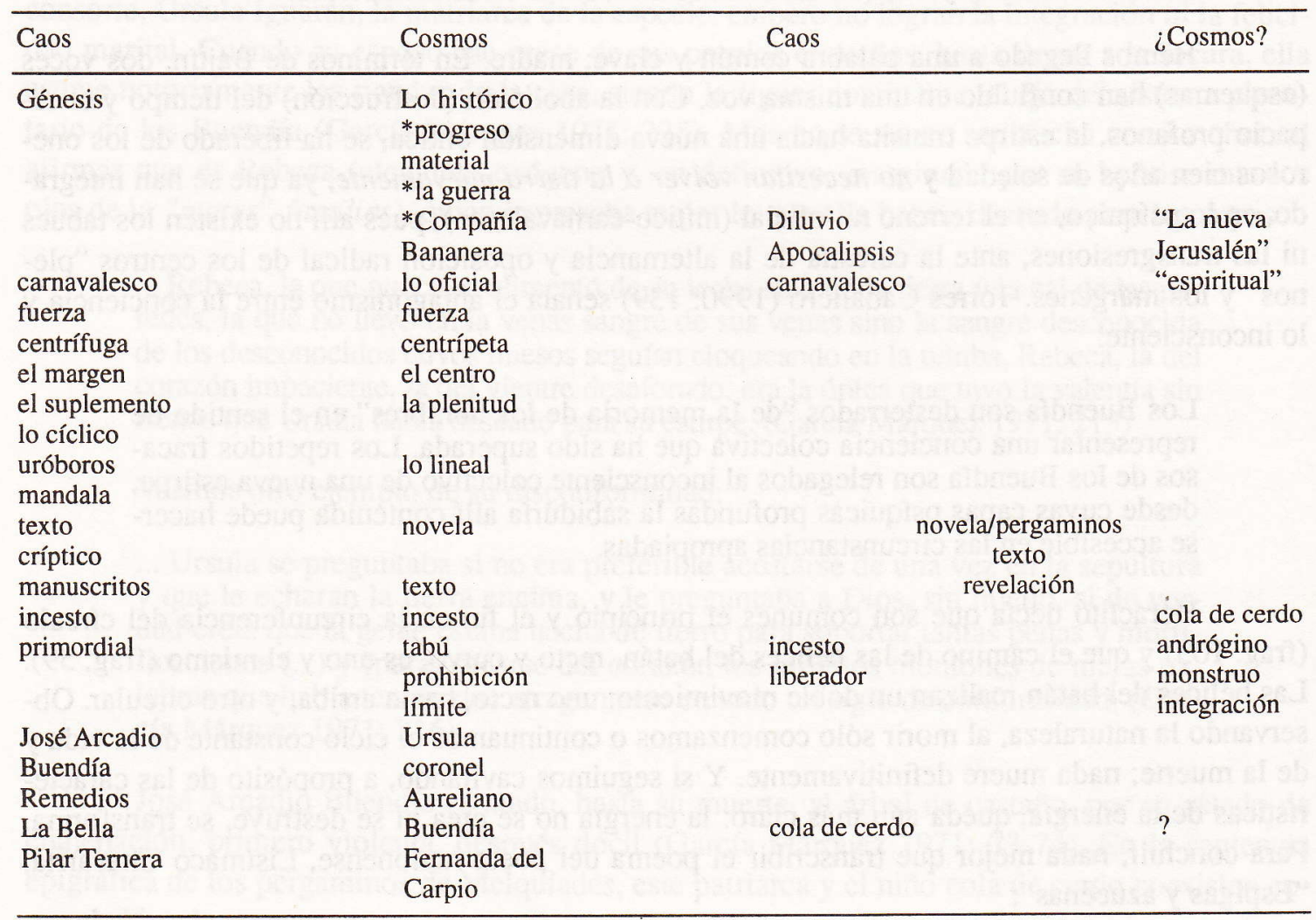




\section{Bibliografia}

Abbagnano, Nicola. 1983. Diccionario de filosofía. México: F.C.E.

Arango, Manuel Antonio. 1979. "La temática y el aspecto social en Cien años de soledad de Gabriel García Márquez". Cuadernos Americanos. 224 (3) 204-216.

Amau, Carmen. 1975. El mundo mítico de Gabriel García Márquez. Barcelona: Península.

Bataille, George. 1985. El erotismo. Barcelona: Tusquests.

Bell-Villada, Gene H. 1991. "Names an Narrative Pattern in One Hundred Years of Solitude". Latin American Literary Review. 9 (18) 37-46.

Borgeson, Paul W. 1984. "Pecado original y salvación en Cien años de soledad". Revista Nacional de Cultura. 46 (52) 41-52.

Brandon, S.G.F. 1975. Diccionario de religiones comparadas. Madrid: Cristiandad.

Camacho Ramírez, Jorge Andrés. 1990. "Deconstruccionismo norteamericano: revolución y tradición". Revista de Filología y Lingüística. 16 (1) 7-13.

Cartín de Guier, Estrella. 1981. Una interpretación de Cien años de soledad. San José: Editoral Costa Rica.

Cirlot, J. Eduardo. 1985. Diccionario de símbolos. Barcelona: Labor.

Culler, Jonathan. 1975. Structuralist Poestics: Structuralism, Linguistics and the Study of Literature. Ithaca: Cornell U.P.

Chevalier, Jean y Alain Gheerbrant. 1988. Diccionario de los símbolos. Barcelona: Herder.

Chinchilla Sánchez, Kattia. 1992. "Mircea Eliade, una clave para la interpretación del pensamiento mítico". Revista Káñina. 16 (1) 207-218.

Chinchilla Sánchez, Kattia. 1994. "José Arcadio Buendía y la lucha demoníaca: Hacia una valoración mística del Rosarium Philosophorum de 1550". Revista de Filología y Lingüistica. 20 (2) (en prensa).

Derrida, Jacques, 1977. Posiciones. Valencia: Pre-texto

Derrida, Jacques. 1986. De la Gramatología. México: Siglo XXI 
Eliade, Mircea. 1981. Tratado de historia de las religiones. Madrid: Cristiandad.

Eliade, Mircea, 1983. Mito y realidad. Barcelona: Labor/Punto Omega.

Eliade, Mircea. 1985. Lo sagrado y lo profano. Barcelona: Labor/ Punto Omega.

Eliade, Mircea. 1992. El mito del eterno retorno. Madrid: Alianza/Emecé.

Fernández, Jesse. 1984. "La ética del trabajo y la acumulación de riqueza en Cien años de soledad". Hispamérica. 13 (37) 73-79

Fields, Wayne. 1987. "One Hundred Years of Solitude and New World Storytelling". Latin American Literary Review. 15 (29) 73-88

Fraile, Guillermo.1982.Historia de la filosofía.Barcelona: B.A.C.

Frazer, James. 1982. La rama dorada. México: F.C.E.

García Márquez, Gabriel. 1971. Cien años de soledad. Buenos Aires: Sudamericana.

Gariano, Carmelo. 1978. "El humor numérico en Cien años de soledad". Hispania. 61 (3) 443-450

Grimal, Pierre. 1984. Diccionario de mitología griega y romana. Barcelona: Paidós.

Gutiérrez Movat, Ricardo. 1982. "Cien años de soledad y el mito farmacopéyico del realismo mágico”. Revista de Estudios Hispánicos. 9 (1) 267-279

Heráclito. 1983. Fragmentos. Barcelona: Orbis.

Jaeck, Louis Marie. 1991. "Cien años de soledad . The End of the Book and the Beginning of Writing”. Hispania. 54 (1) 50-56.

Jelinski, Jack B. 1984. "Memory and Remembered Structure of Cien años de soledad". Revista de Estudios Hispánicos. 18 (3) 323-333

Jung, Carl G. 1974. El hombre y sus símbolos. Madrid: Aguilar.

Jung,Carl G.1982. Símbolos de transformación. Barcelona: Paidós.

Lerner, Isaías. 1972. "A propósito de Cien años de soledad”. En: Giacoman (ed.), Homenaje a Gabriel García Márquez, 260-275. Madrid: Las Américas. 
Levine, Susanne L. 1971. "La maldición del incesto en Cien años de soledad". Revista Iberoamericana. 37 (76-77) 50-56.

Levine, Susanne L. 1975. El espejo hablado. Caracas: Monte Ávila.

Libânio, Juan B. y Ma. Clara L.Bingemer. 1985. Escatología cristiana. Buenos Aires: Ediciones Paulinas.

López, Angel. 1986. "De la ficción y la realidad y las funciones de la realidad del lenguaje en Cien años de soledad". Revista Canadiense de Estudios Hispánicos. 10 (3) 389-405

Ludmer, Josefina. 1974. Cien años de soledad: una interpretación. Buenos Aires: Tiempo Contemporáneo.

Mac Murray, George. 1977. Gabriel García Márquez. New York: Frederik Ungar Publishing Co.

Malinowski, Bronislaw. 1974. Sexo y represión en la sociedad primitiva. Buenos Aires: Nueva Visión.

Malinowski, Bronislaw. 1982. Estudios de psicología primitiva. Barcelona: Paidós.

Mann, Thomas. 1964. Obras escogidas. Madrid: Aguilar.

Maturo, Graciela. 1972. Claves simbólicas de García Márquez. Buenos Aires: Fernando García Cambeiro.

Montaner Ferrer, María Eulalia. 1987. "Falaz García Márquez: Ursula Iguarán, narradora en Cien años de soledad." Hispanic Review. 55 (1) 77-93

Müller, Max. 1990. Mitología egipcia. Barcelona: Edicomunicación.

Ortega, Julio. 1972. "Cien años de soledad". En: Giacoman(ed), Homenaje a Gabriel García Márquez,173-183.Madrid: Las Américas.

Ortega, Julio. 1984. "La risa de la tribu. Los signos del intercambio en Cien años de soledad". Nueva Revista de Filología Hispánica. 33 (2) 396-430

Palencia-Roth, Michael. 1981. "La imagen del Uróboros: el incesto en Cien años de soledad." Cuadernos americanos. 237 (4) 67-81

Palencia-Roth, Michael. 1983. Gabriel García Márquez. La línea, el círculo y las metamorfosis. Madrid: Gredos. 
Parkinson-Zamora, Lois. 1982. "The end of innocence: myth and narrative structure in Faulkner's Absalom Absalom! and García Márquez's Cien años de soledad'. Hispanic Journal. 4 (1) 23-40.

Rodríguez Monegal, Emir. 1972. "Novedad y Anacronismo en Cien años de soledad". En Giacoman (ed), Homenaje a Gabriel García Márquez, 15-42. Madrid: Las Américas.

Rulfo, Juan. 1978. Pedro Páramo. Barcelona: Planeta.

Sacerio-Gari, Enrique. 1987. “Las flores de Borges en García Márquez”. Hispania. 70 (1) 62-66

Sagrada Biblia. 1957. New York: Grolier.

Saldívar, José David. 1985. "Ideology and Deconstruction in Macondo". Latin American Literary Review. 13 (25) 26-43

Sims, Robert L. 1988. "Periodismo, ficción, espacio carnalesco y oposiciones binarias: la creación de la infraestructura novelística de Gabriel García Márquez”. Hispania. 71 (1) 50-60.

Sófocles. 1980. Las siete tragedias. México: Porrúa.

Torres Caballero, Benjamín. 1990. “La estructura urobórica de Cien años de soledad". Hispanic Journal. 11 (2) 137-154

Valverde Barrenechea, Leticia. 1983. "Ursula, Petra Cotes y Pilar Ternera: Una tríada mítica de lo inconsciente colectivo". Revista Káñina. 7 (2) 43-57

Vargas Llosa, Mario. 1971. García Márquez: Historia de un deicidio. Caracas: Monte Avila.

Virgilio. 1961. La Eneida, Bucólicas y Geórgicas. México: Ed. Nacional.

Vries, Ad de. 1984. Dictionary of symbols and Imagery. Netherlands: Elsevier Science Publishing Company Inc.

Wahnón, Sultana. 1994. "Las claves judías de Cien años de soledad". Cuadernos hispanoamericanos. Abril. 93-104.

Watson, Richard A. 1987 “A Pig's Tail”. Latin American Literary Review. 15 (29) 89-92.

Williams, Linda L. 1977. "Edenic Nostalgia and Play of Mirrors in Hopscotch and One Hundred Years of Solitude." Latin American Literary Review. 6 (11) 53-67. 